\title{
Structural dynamics of the yeast Shwachman- Diamond syndrome protein (Sdo1) on the ribosome and its implication in the 60S subunit maturation
}

\author{
Chengying Ma ${ }^{1}$, Kaige Yan ${ }^{1}$, Dan Tan ${ }^{2,3}$, Ningning Li ${ }^{1}$, Yixiao Zhang ${ }^{1}$, Yi Yuan ${ }^{1}$, Zhifei Li ${ }^{1}$, Meng-Qiu Dong ${ }^{2,3}$, \\ Jianlin Lei ${ }^{1}$, Ning Gao ${ }^{1 \bowtie}$ \\ 1 School of Life Sciences, Tsinghua University, Beijing 100084, China \\ ${ }^{2}$ National Institute of Biological Sciences, Beijing 102206, China \\ ${ }^{3}$ Graduate Program in Chinese Academy of Medical Sciences and Peking Union Medical College, Beijing 100730, China \\ $\triangle$ Correspondence: ninggao@tsinghua.edu.cn (N. Gao) \\ Received December 4, 2015 Accepted December 14, 2015
}

\begin{abstract}
The human Shwachman-Diamond syndrome (SDS) is an autosomal recessive disease caused by mutations in a highly conserved ribosome assembly factor SBDS. The functional role of SBDS is to cooperate with another assembly factor, elongation factor 1-like (Efl1), to promote the release of eukaryotic initiation factor 6 (elF6) from the late-stage cytoplasmic 605 precursors. In the present work, we characterized, both biochemically and structurally, the interaction between the 605 subunit and SBDS protein (Sdo1p) from yeast. Our data show that Sdo1p interacts tightly with the mature $60 \mathrm{~S}$ subunit in vitro through its domain I and II, and is capable of bridging two $60 \mathrm{~S}$ subunits to form a stable 2:2 dimer. Structural analysis indicates that Sdo1p bind to the ribosomal P-site, in the proximity of uL16 and uL5, and with direct contact to $\mathrm{H} 69$ and $\mathrm{H} 38$. The dynamic nature of Sdo1p on the $60 \mathrm{~S}$ subunit, together with its strategic binding position, suggests a surveillance role of Sdo1p in monitoring the conformational maturation of the ribosomal P-site. Altogether, our data support a conformational signal-relay cascade during late-stage $60 \mathrm{~S}$ maturation, involving uL16, Sdo1p, and Efl1p, which interrogates the functional P-site to control the departure of the anti-association factor elF6.
\end{abstract}

Electronic supplementary material The online version of this article (doi:10.1007/s13238-015-0242-5) contains supplementary material, which is available to authorized users.
KEYWORDS ribosome biogenesis, SBDS, SDS, Sdo1, cryo-electron microscopy (cryo-EM)

\section{INTRODUCTION}

Protein biosynthesis is catalyzed by the ribosome in all living organisms. Thousands of ribosomes must be synthesized per minute to maintain and update the tremendous protein inventory in rapidly growing cells. Ribosomal subunit assembly in vivo is a highly complex process, which composes of a large number of intertwined ribosomal protein (RP) binding and rRNA maturation (rRNA folding, processing, modification and assembly) events. In eukaryotes, additional complexity is added, as the assembly starts in the nucleolus and involves the import of RPs and associated factors, as well as the export of premature ribosomal particles (66S and $43 \mathrm{~S}$ pre-ribosomes) across nuclear membrane. Final maturation of the pre-ribosomes takes place in cytoplasm, and is coupled to the regulation of translation initiation (Karbstein, 2013; Lebaron et al., 2012; Miluzio et al., 2009; Soudet et al., 2010; Strunk et al., 2012). In Saccharomyces cerevisiae, the complete maturation of translationally active $60 \mathrm{~S}$ and $40 \mathrm{~S}$ subunits from extremely long rRNA transcripts and 79 RPs requires more than 70 small nucleolar RNAs (snoRNAs) and 200 assembly factors (AFs) (Panse and Johnson, 2010; Woolford and Baserga, 2013). Many of these factors function primarily on the quality control of subunit production, acting at various maturation checkpoints during the assembly process. These checkpoints often involve regulated binding and release of a series 
of factors (Karbstein, 2013; Lo et al., 2010; Matsuo et al., 2014).

Cellular defects in ribosome biogenesis caused by assembly factor insufficiency or mutations result in arrests of assembly at different checkpoints during cell cycle progression (Bernstein et al., 2007; Dez and Tollervey, 2004; Jorgensen et al., 2002). More importantly, disorders in ribosome biogenesis, which induce a nucleolar stress (Boulon et al., 2010) that is monitored by the Mdm2/Hdm2-p53 pathway (Chakraborty et al., 2011; Deisenroth and Zhang, 2010), were shown to be associated with increased cancer susceptibility in animal cells (Montanaro et al., 2008; Ruggero and Pandolfi, 2003). In human, a diverse collection of genetic diseases, named as ribosomopathies, have been linked to mutations in ribosomal proteins or AFs (Chakraborty et al., 2011; Freed et al., 2010; Narla and Ebert, 2010; Teng et al., 2013). Besides their specific clinical phenotypes, patients with ribosomopathies have a predisposition to a variety of cancers. Among these diseases, ShwachmanDiamond syndrome (SDS) is an autosomal recessive disease with multi-system disorders caused by mutations in the highly conserved Shwachman-Bodian-Diamond Syndrome gene (SBDS) (Boocock et al., 2003). Clinical characteristics associated with SDS are pancreatic insufficiency, skeletal abnormalities and bone marrow failure with neutropenia, ineffective hematopoiesis, and increased risk of leukemia (Narla and Ebert, 2010). Most of SDS patients ( 90\%) are associated with mutations of SBDS gene that result in premature truncation of SBDS protein (Austin et al., 2005; Boocock et al., 2003).

SBDS is a highly conserved protein in archaea and eukaryotes (Boocock et al., 2006; Shammas et al., 2005). Converging cell biology data on several SBDS homologues, including yeast (Sdo1p) (Lo et al., 2010; Luz et al., 2009; Menne et al., 2007; Moore et al., 2010; Savchenko et al., 2005), mouse (Finch et al., 2011), Dictyostelium discoideum (Wong et al., 2011) and human SDS patient cells (Burwick et al., 2012; Ganapathi et al., 2007; Wong et al., 2011) have implicated a functional role of SBDS in the maturation of the $60 S$ ribosomal subunit. Specifically, SBDS was proposed to coordinate with elongation factor-like 1 (Efl1p) to release elF6 (Tif6p in yeast), an important 60S shuttling factor, from late cytoplasmic pre-60S particles. Failure in the timely release and recycling of Tif6p impairs the subunit joining and subsequent translation initiation (Karbstein, 2013; Miluzio et al., 2009). The structures of SBDS from several species have been resolved (de Oliveira et al., 2010; Finch et al., 2011; Ng et al., 2009; Shammas et al., 2005), which contain three structural domains, I to III (numbered from the N-terminus). The N-terminal domain of SBDS was shown to be involved in RNA binding (de Oliveira et al., 2010) and domains II-III were found to interact with an insertion domain of Efl1p (Asano et al., 2014). Also, recent data revealed a functional link between Sdo1p and uL16 (RPL10), which is a late-binding protein during $60 \mathrm{~S}$ assembly (Gamalinda et al., 2014). It was shown that the loop of uL16 residing in the ribosomal P-site is important for the activation of Efl1p to induce the release of Tif6p (Bussiere et al., 2012). Furthermore, uL16 was shown to be involved in the recruitment of Sdo1p (Sulima et al., 2014a), and a role of Sdo1p/SBDS as a nucleotide exchange factor to stabilize the binding of GTP to Efl1p was proposed (Gijsbers et al., 2013).

Despite the functional framework that defines a pathway for SBDS protein family as described above, its biochemical property that contributes to its involvement in the cytoplasmic recycling of Tif6 $p$ and ribosomal $\mathrm{P}$-site maturation remains unclear. In this report, using cryo-electron microscopy (cryo-EM) and several complementary approaches, we performed structural and biochemical characterization of the interaction between the yeast SBDS homologue, Sdo1p and the $60 S$ subunit. Our data reveal that Sdo1p binds to the ribosomal P-site and directly contacts $\mathrm{H} 69$ and $\mathrm{H} 38$ of the 25S rRNA. Moreover, owing to its structural flexibility, Sdo1p displays a dynamic behavior on the 605 subunit, with wobbling terminal domains (II and III). Very interestingly, Sdo1p is able to induce dimerization of the 605 subunits in a very specific manner. Together with published data, our results suggest that Sdo1p is an essential surveillance factor for the 605 maturation, which monitors the conformational status of the ribosomal P-site, including surrounding uL16, H69 and $\mathrm{H} 38$, and couples, through Efl1p, the maturation of the ribosomal $\mathrm{P}$-site to the release of Tif6p.

\section{RESULTS}

\section{Sdo1p binds to the mature $60 \mathrm{~S}$ subunit in vitro}

Previous data showed that Sdo1p co-fractionated with the pre-60S fractions (Menne et al., 2007) and bound to all forms of rRNA in vitro (Luz et al., 2009). It is not clear whether Sdo1p could bind to the mature form of the $60 S$ subunit. This prompted us to examine the interaction between the mature $60 \mathrm{~S}$ subunit and Sdo1p by gel filtration analysis. As shown in Fig. $1 \mathrm{~A}$ and $1 \mathrm{~B}, \mathrm{Sdo} 1 \mathrm{p}$ co-elutes with the $60 \mathrm{~S}$ subunit, and forms a stable complex with the mature 605 subunit.

\section{Sdo1p induces dimerization of 605 subunits in vitro}

Next, we applied cryo-EM to analyze the 60S complex bound with Sdo1p, aiming at determining the Sdo1p binding site in a minimal system. The resulting images of the $605-$ Sdo1p complex show a relatively even distribution, without undesired aggregation or precipitation (Fig. 1C). However, unexpectedly, defined oligomers of 605 subunits were also detected. In addition to well separated mono-disperse $60 \mathrm{~S}$ monomers, many $60 \mathrm{~S}$ subunits were found to exist in a dimeric or trimeric state (Fig. 1C). The gel filtration analysis does not have enough resolution at its high molecular weight boundary, therefore, we employed sucrose density gradient centrifugation (SDGC) to confirm this observation. However, in contrast to the cryo-EM results, there were no apparent changes in the sedimentation profiles of the $60 \mathrm{~S}$ subunit in 
A

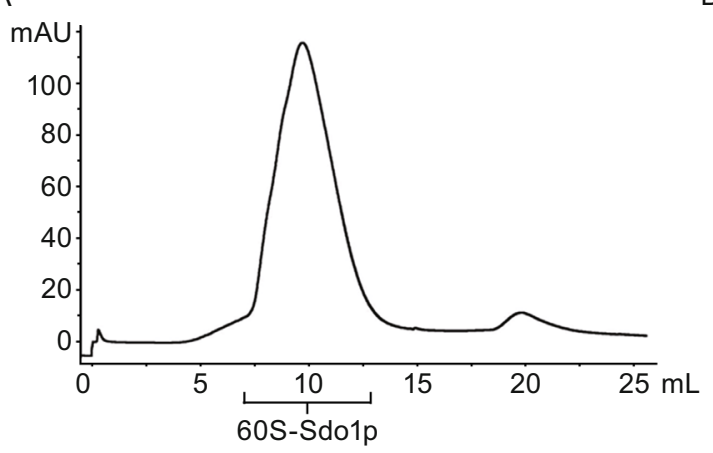

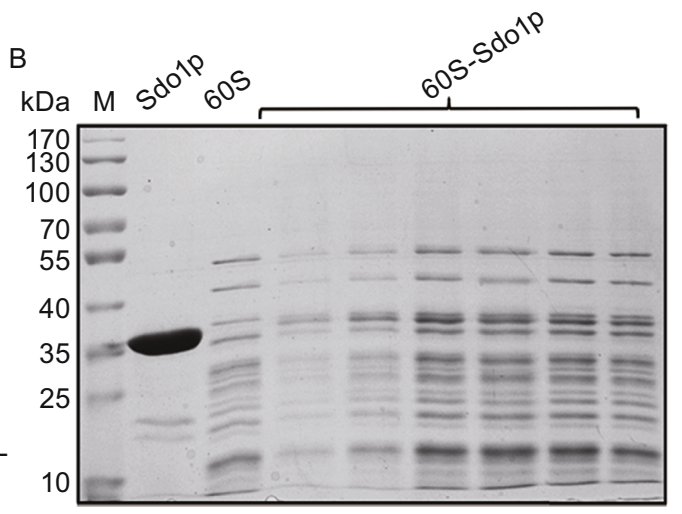

$\mathrm{D}$



$1: 5$

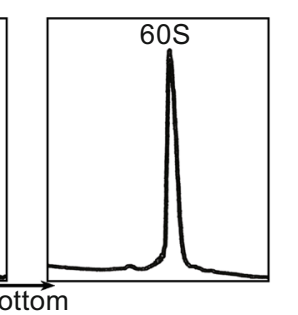

1:10




Figure 1. Sdo1p binds to the mature $60 \mathrm{~S}$ subunit in vitro. (A) Gel filtration trace of the 60S-Sdo1p complex monitored by UV absorption at $280 \mathrm{~nm}$. (B) SDS-PAGE examination of fractions labelled in (A). M, maker lane; Sdo1p, loading input containing Sdo1p only; 60S, loading input containing 60S only. (C) A representative cryo-EM micrograph of the 60S-Sdo1p complex (without crosslinking). Particles of 605 dimers and trimers are highlighted by yellow and red circles, respectively. (D) Examination of the formation of $60 \mathrm{~S}$ dimers by Sdo1p using sucrose density gradient centrifugation. 5-, 10- or 20-fold excess of Sdo1p was incubated with the 60 s subunit in the absence $(-G)$ or presence $(+G)$ of $0.1 \%$ glutaraldehyde.

the presence of 5-, 10- and 20-fold excess of Sdo1p (Fig. 1D, upper panel). We reason that the seemingly discrepancy between the two approaches might be explained by the weak association between the two 60S subunits which might not sustain a long-time centrifugation. Indeed, upon addition of a chemical crosslinker $(0.1 \%$ glutaraldehyde) in the reaction system, an additional peak, corresponding to the 60S dimer, appears on the gradient profile. Dimerization of $60 \mathrm{~S}$ subunits by Sdo1p is clearly concentration dependent: in 5-fold excess of Sdo1p, most of the $60 \mathrm{~S}$ subunits are still in monomeric state; in 10-fold excess, around $40 \%$ of 60 s subunits are dimers; in 20 -fold excess, the majority of the $60 \mathrm{~S}$ subunits are in dimer, and tiny peaks corresponding to higher order oligomers start to emerge (Fig. 1D, lower panel). And the empty 605 subunits could not form dimer with $0.1 \%$ glutaraldehyde (Fig. S1).

\section{Sdo1p does not induce oligomerization of $40 \mathrm{~S}$ or $80 \mathrm{~S}$ ribosomes}

Following above observations, we tested whether Sdo1p had any effects on the sedimentation profiles of a mixture of $40 \mathrm{~S}$ and $60 \mathrm{~S}$ subunits $\left(2.5 \mathrm{mmol} / \mathrm{L} \mathrm{Mg}^{2+}\right)$ or $80 \mathrm{~S}$ ribosomes $\left(12 \mathrm{mmol} / \mathrm{L} \mathrm{Mg}^{2+}\right)$ using SDGC. As shown in Fig. 2, addition of Sdo1 has no effect on the 40S or the 80S ribosome, except that it again preferentially dimerizes the $60 \mathrm{~S}$ subunits in the reaction mixtures. And the effect is more apparent in the presence of glutaraldehyde and when the free 605 subunit is abundant (Fig. 2C, lower panel). Due to the equilibrium of $80 \mathrm{~S}$ association and dissociation, there would be a certain amount free $60 \mathrm{~S}$ subunit in the $80 \mathrm{~S}$ mixture even in the associating condition $\left(12 \mathrm{mmol} / \mathrm{L} \mathrm{Mg}^{2+}\right)$, and as expected, Sdo1p only specifically dimerizes those $60 \mathrm{~S}$ 
A
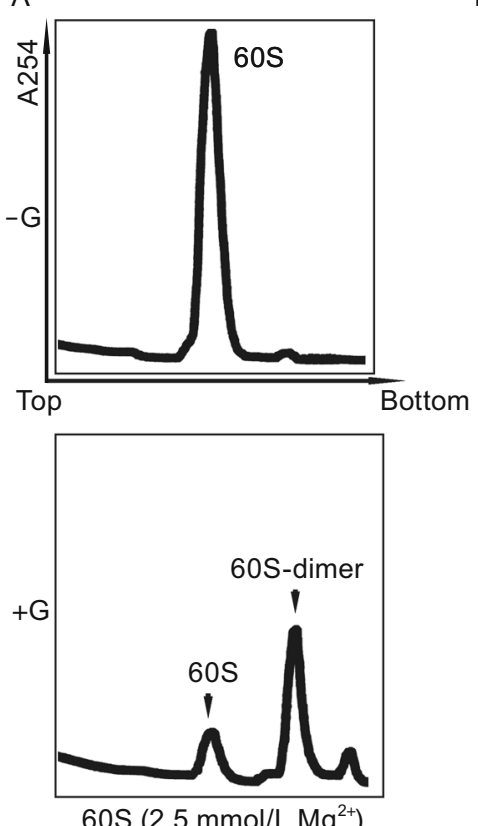

D
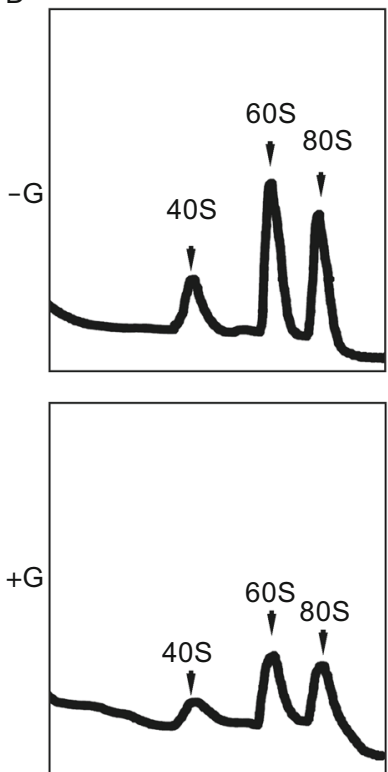

$80 \mathrm{~S}\left(2.5 \mathrm{mmol} / \mathrm{L} \mathrm{Mg}^{2+}\right)$


$\mathrm{E}$
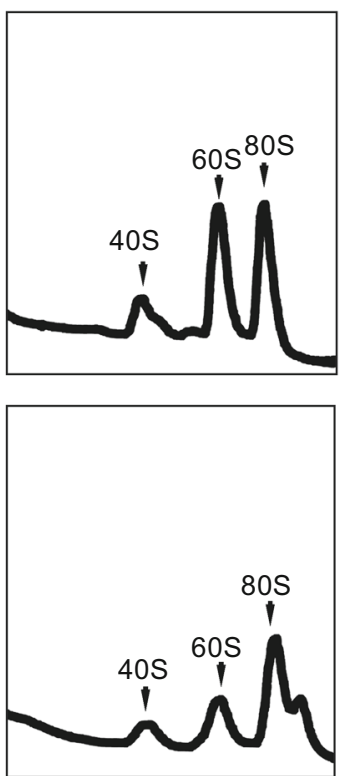

$80 \mathrm{~S}+\operatorname{Sdo} 1 \mathrm{p}\left(2.5 \mathrm{mmol} / \mathrm{L} \mathrm{Mg}^{2+}\right)$
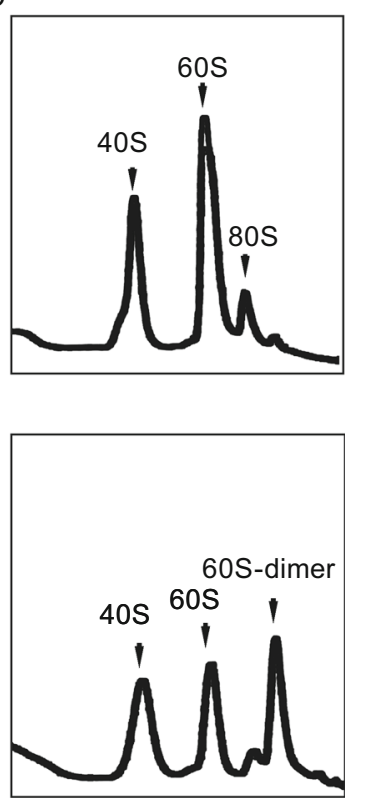

$40 \mathrm{~S}+60 \mathrm{~S}+\operatorname{Sdo} 1 \mathrm{p}\left(2.5 \mathrm{mmol} / \mathrm{L} \mathrm{Mg}^{2+}\right)$

$\mathrm{F}$
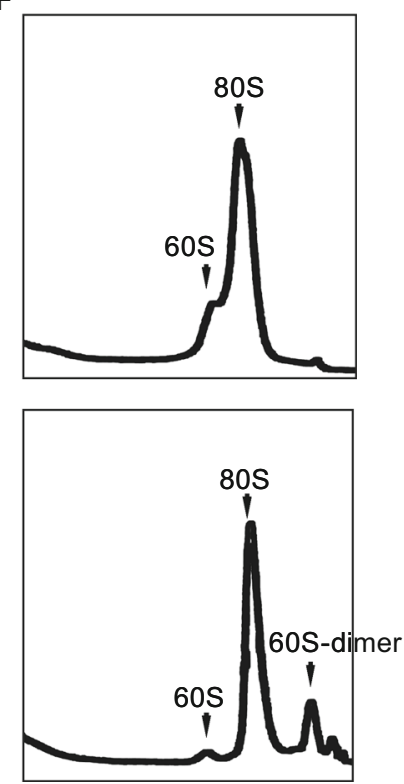

$80 \mathrm{~S}+\operatorname{Sdo} 1 \mathrm{p}\left(12 \mathrm{mmol} / \mathrm{L} \mathrm{Mg}^{2+}\right)$

Figure 2. Sdo1p only specifically induces $60 \mathrm{~S}$ dimerization but not $40 \mathrm{~S}$ or $80 \mathrm{~S}$ ribosome. (A) Sdo1p induces the formation of dimers of $60 S$ subunits. (B) A mixture of the $40 \mathrm{~S}$ and 60 S subunits in dissociating condition $\left(2.5 \mathrm{mmol} / \mathrm{L} \mathrm{Mg}^{2+}\right)$, in the absence $(-\mathrm{G}$, top panel) or presence $(+G$, bottom panel) of $0.1 \%$ glutaraldehyde, were subjected to SDGC, indicating that glutaraldehyde alone has no effect on dimer formation. (C) Same as (B), but with 20-fold excess of Sdo1p supplied. (D) $80 \mathrm{~S}$ ribosomes in dissociating condition, showing a partial dissociation of $80 S$ into $40 S$ and 60 S subunits. (E) Same as (D), but with 20 -fold excess of Sdo $1 \mathrm{p}$ supplied indicated that Sdo1p do not induce $40 \mathrm{~S}$ and $80 \mathrm{~S}$ ribosome dimerization but only $60 \mathrm{~S}$. (F) $80 \mathrm{~S}$ ribosomes in associating condition (12 $\left.\mathrm{mmol} / \mathrm{L} \mathrm{Mg}^{2+}\right)$, treated with Sdo1p in the absence or presence of glutaraldehyde also showed Sdo1p do not induce $80 \mathrm{~S}$ ribosome dimerization.

subunits without apparent effect on the $80 \mathrm{~S}$ ribosomes (Fig. 2F). The same experiment of Sdo1p on the $80 \mathrm{~S}$ ribosomes was repeated in low $\mathrm{Mg}^{2+}$ condition $(2.5 \mathrm{mmol} / \mathrm{L})$.
805 ribosomes largely dissociate into 605 and 405 subunits in this dissociating condition (Fig. 2D), and the dissociated $60 \mathrm{~S}$ subunits could be cross-linked by Sdo1p (Fig. 2E). 
However, in both of the high and low $\mathrm{Mg}^{2+}$ conditions, Sdo1p did not change the peak heights of the $80 S$ ribosome (Fig. 2E and 2F), suggesting that the binding site of Sdo1p on the $60 S$ subunit is highly likely at the inter-subunit face of the 605 subunit.

Based on the above observations, we conclude that Sdo1p preferentially binds to the $60 \mathrm{~S}$ subunit, and is capable of promoting weak dimerization of mature $60 \mathrm{~S}$ subunits. This reminds us of the recent observation that $80 S$ ribosomes are capable of forming $80 \mathrm{~S}-80 \mathrm{~S}$ and $80 \mathrm{~S}-60 \mathrm{~S}$ dimers in vivo under amino acid depletion (Krokowski et al., 2011). Therefore, the 60S-60S dimer might also be a form of resting translation machinery induced by certain stresses, which appears to be in general consistent with previous reports showing that loss of SBDS in HEK293 or HeLa cells leads to increased sensitivity to various stresses (Ball et al., 2009; Watanabe et al., 2009).

Domains I and II of Sdo1p are responsible for the 60S binding and dimerization

To map the domains of Sdo1p responsible for the binding and dimerization of the 60S subunit, we further characterized the binding of individual domains of Sdo1p to the 60S subunit. In human, SDS is an autosomal recessive disorder and mostly associated with two predominant mutations, 183-184TA to CT that results in an in-frame stop codon (K62X) and $258+2 \mathrm{~T}$ to $\mathrm{C}$ that produces premature truncation (84Cfs3) (Boocock et al., 2003), both of which would render truncated forms of SBDS lack of C-terminal domains. Therefore, we constructed a series of Sdo1p truncations to test the ability of mutant proteins in the $60 \mathrm{~S}$ binding and dimerizing abilities, including three individual domain constructs (I, II and III), and two truncations of terminal domains (I-II and II-III) (Fig. 3A).

Firstly, we tested the ability of these mutants in the $60 \mathrm{~S}$ subunit dimerization by SDGC in the presence of chemical crosslinker. As shown in Fig. 3B, only the construct of domain $\mathrm{I}-\mathrm{II}$ is capable of inducing the formation of 60S-60S dimer, and its dimerizing activity is also concentration-dependent (Fig. 3C). At a higher excess of domains I-II mutant (20-fold), a significant peak corresponding to trimers appears on the gradient profile. Next, we examined the binding of Sdo1p mutants to the $60 \mathrm{~S}$ subunit by co-sedimentation assay. The reaction mixtures were subjected to a $33 \%$ sucrose cushionbased centrifugation and the binding was detected by TricineSDS-PAGE (Fig. 3D). Our results showed that similar to the full-length Sdo1p, constructs of domain I, II, and I-II all display clear binding to the $60 \mathrm{~S}$ subunit. Very weak binding of construct II-III could also be detected. In contrast, no binding of domain III construct was detected. Lastly, in order to quantitatively compare the binding of these mutants to the $60 \mathrm{~S}$ subunit, we measured the affinities of these mutants to the $60 \mathrm{~S}$ subunit using Bio-layer interferometry (BLI) (Figs. $3 \mathrm{E}$ and S2). Highly consistent with the co-sedimentation data, construct of the domain I-II display the highest affinity to the 60 S subunit $\left(K_{D}=15 \mathrm{nmol} / \mathrm{L}\right)$, comparable to the full-length protein $\left(K_{D}=18 \mathrm{nmol} / \mathrm{L}\right)$ (Fig. S2A and S2E). The truncated domain I, II and II-III display modest level of affinities $\left(K_{D}\right.$ ranging from 25-40 nmol/L) (Fig. S2B, S2C and S2F). In sharp contrast, domain III had no detectable binding (Fig. S2D).

From these results, a clear conclusion could be drawn: domain I of Sdo1p is the major RNA binding domain, while domain III has no RNA binding activity.

\section{D image analysis of the 60S-Sdo1p complexes}

Knowing that different oligomeric states of the 60S-Sdo1p complexes could form, we processed cryo-EM images according to the particle sizes. Particles representing dimers were selected and subjected to reference-free alignment and classification by RELION (See MATERIALS AND METHODS). As shown in Fig. 4A, many populated class-average images show well resolved structural features for both $60 \mathrm{~S}$ subunits, indicating that inter-subunit connection could be rather rigid (Fig. 4A). Interestingly, these 2D average images display an apparent 2-fold symmetry. This observation demonstrates that the dimer induced by Sdo1p is a specific structural entity, and not from random aggregation of $60 \mathrm{~S}$ subunits or Sdo1p. Nevertheless, many average images have defined structural details only for one 605 subunit, with a smeared density blob for the other, suggesting that a certain extent of flexibility for the inter-subunit connection. A simple explanation for different orientations of two subunits within dimers is that Sdo1p and the 60S subunit could exist in different stoichiometry. In rigid dimers, the $60 \mathrm{~S}$ subunit and Sdo1p are present in a 2:2 ratio, as two copies of Sdo1p would further "staple" two subunits to fix their relative orientation. In contrast, in loose dimers, one copy of Sdo1p is capable of bridging the two subunits, but the high inter-domain flexibility of Sdo1p (de Oliveira et al., 2010) would allow a wobbling between two subunits.

\section{D structure of the 60S-60S dimer}

From 2D image analysis, the $60 \mathrm{~S}$ subunit and Sdo1p could form stable 60S-60S dimers, which should enable the 3D structural determination of dimers by single particle analysis. Towards this end, different 3D classification strategies were tested on particles of dimers, and both the symmetry-free and 2-fold symmetric reconstructions were explored (Fig. S3). The 3D classification was done using RELION in a multi-round way. After the first round (C2-imposed), particles with 3D class structures showing relatively rigid dimers were kept for further analysis. Following steps were carried out without imposing two-fold symmetry. As a result, only $11 \%$ of particles displayed structural details for both 605 subunits, and structural refinement from these particles rendered a final density map at $14-\AA$ resolution (Fig. S3B). This is expected, as 2D image analysis indicates that many dimers 

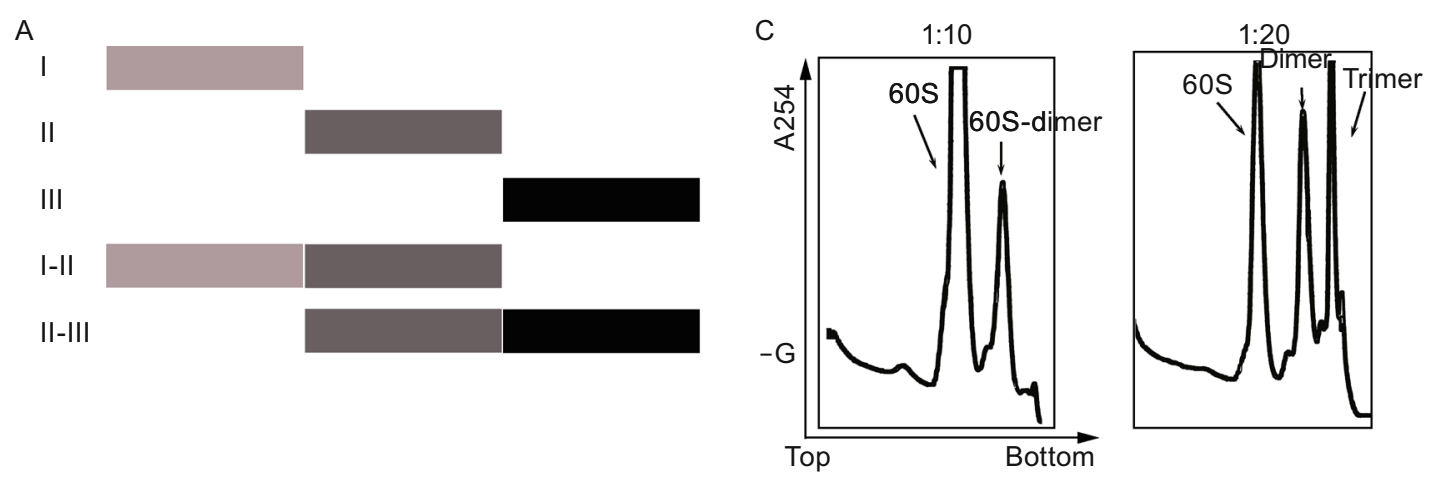

B
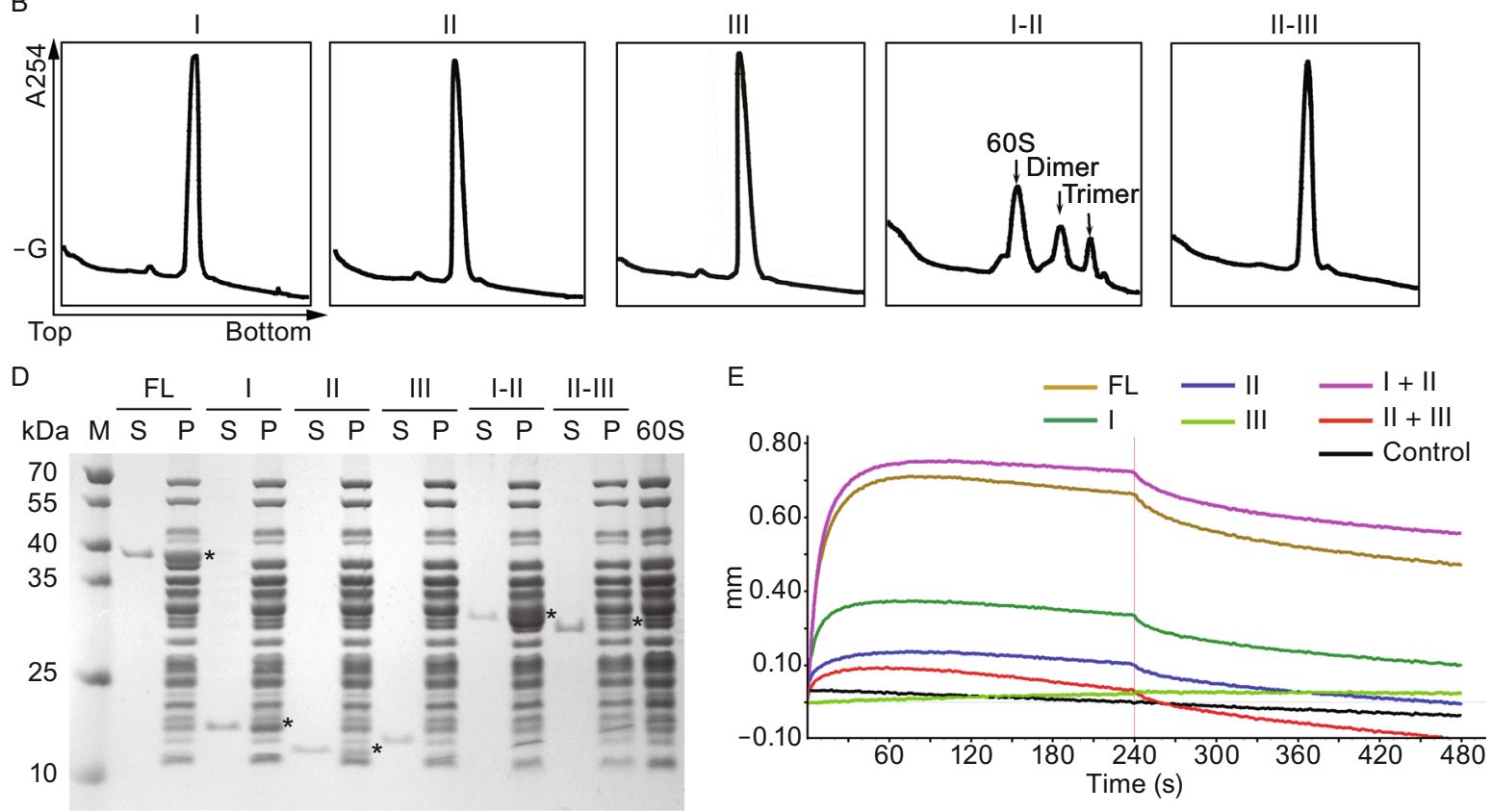

Figure 3. Sdo1p induced 60 S dimerization through domain I-II. (A) Schematic overview of the Sdo1p variants. (B) Formation of $60 \mathrm{~S}$ dimers by Sdo1p variants (20-fold excess) examined by SDGC. (C) The formation of $60 \mathrm{~S}$ dimers by Sdo1p domains I-II is concentration dependent. (D) The binding of Sdo1p variants to the mature $60 \mathrm{~S}$ subunit examined by co-sedimentation assay. FL, fulllength; S, supernatant; P, pellet. $(E)$ The binding of Sdo1p variants to the mature 60S subunit examined by Bio-layer interferometry. Both the association and dissociation reactions were carried out for $240 \mathrm{~s}$.

are not rigid dimmers (Fig. 4A). Using the crystal structure of the 60 S subunit as template (Ben-Shem et al., 2011), additional densities between the two $60 \mathrm{~S}$ subunits can be segmented (Fig. 4B-D). This mass of densities is sandwiched between $\mathrm{H} 69$ of one $60 \mathrm{~S}$ subunit and $\mathrm{H} 38$ of the other $60 \mathrm{~S}$ subunit.

The homology model of yeast Sdo1p was predicted by I-TASSER (Roy et al., 2010) and fitted into the cryo-EM density map (Fig. 4D). The additional densities between two $60 S$ subunit allowed the docking of two copies of Sdo1p. Although the resolution of our map (14 $\AA$ ) could not provide unambiguous assignment of individual domains into the density map, the relative orientation of individual domains on the $60 \mathrm{~S}$ subunit could be fixed (Fig. 3) by integrating the very recent cryo-EM data of a chimerical 60S-SBDS complex (Weis et al., 2015), which revealed that domain I lies in the P-site. Very interestingly, the recent data also showed that domain II-III could exist in very different conformations, owing to the flexible linker between domain I and domain II (Weis et al., 2015). As a result, we built a model for the 60S-Sdo1p dimer (Fig. 4D), which requires a large reorientation of domain II-III (Fig. 4E), compared with the homology model of Sdo1p. The model could well explain the structural basis for the observed dimerization of $60 \mathrm{~S}$ subunits by Sdo1p: domain I interacts with the ribosomal P-site of one subunit, while domains II-III (mostly II) interact with H38 of the other subunit. 
A

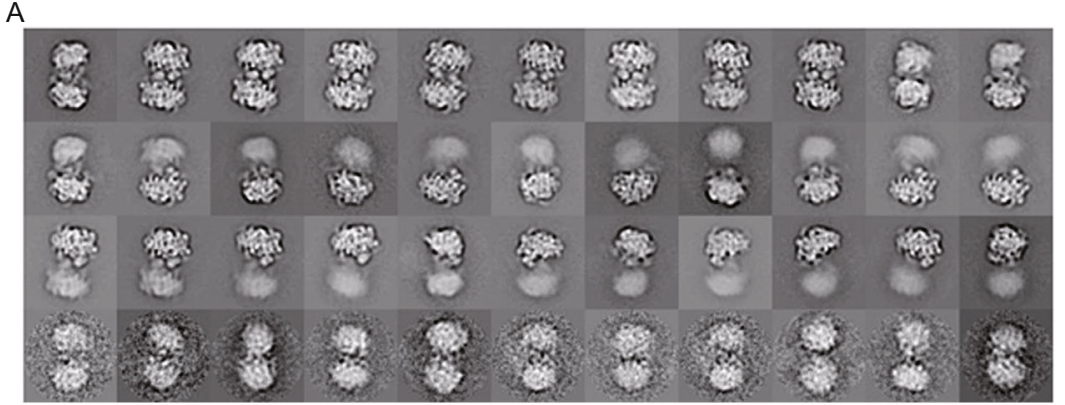

$\mathrm{E}$



B


D

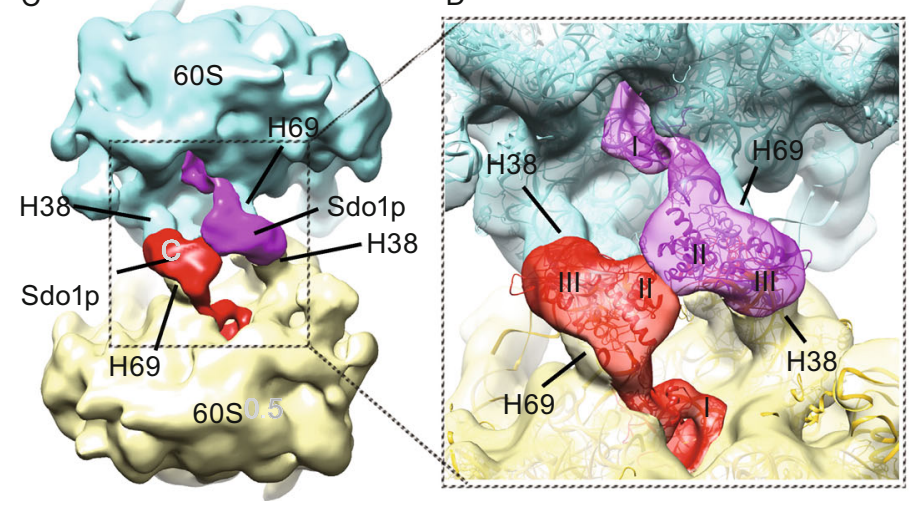

Figure 4. The cryo-EM structure of dimeric 60S-Sdo1p complex. (A) Reference-free 2D classification of selected particles of the 605 dimers. (B) Overview of cryo-EM density map of the dimeric 60S-Sdo1p complex, superimposed with fitted models. (C) Same as (B), but with two $60 S$ subunits and two copies of Sdo1p separately colored. (D) Zoom-in view of boxed region in (C). (E) Comparison of Sdo1p in its 60S-bound conformation with that derived from homology modelling (see MATERIALS AND METHODS).

Interaction of Sdo1p with the 605 subunit is highly dynamic and might involve uL16

The relatively low population of the stable 605 dimers in cryo-EM images hampered the resolution of the dimer density map. We, therefore, sought to improve the structure by only processing the monomeric 605 particles. As a result, we prepared another batch of sample using 10-fold excess of Sdo1p in the 60S binding and only picked well-separated 605 particles from cryo-EM images. Although with a much larger dataset (305,370 particles), exhaustive 3D classification did not reveal high-resolution densities for Sdo1p. When more particles were included for final refinement, as expected, we could only obtain a high-resolution structure for the $60 S$ subunit. In contrast, when a small homogenous fraction of particles were used, an additional piece of density could be seen in the ribosomal P-site. (Fig. S4). Based on our domain assignment in the $60 \mathrm{~S}$ dimer, it is likely domain I of Sdo1p.

To further confirm our structural and biochemical data that Sdo1p binds to the ribosomal P-site, we employed crosslinking based mass spectrometry (CX-MS) (Singh et al., 2010), which is particularly useful for structural analysis of flexible and transient interactions. Therefore, we treated the 60S-Sdo1p complex with cross-linking reagents disuccinimidyl suberate (DSS) and bis(sulfosuccinimidyl) suberate
$\left(B S^{3}\right)$, and subjected the linked sample to mass spectrometry. The reactive sites of the cross-linkers interact with the primary amino group of lysine and $\mathrm{N}$-terminal tail of the protein. Considering the 11.4- $\AA$ spacer arm between reactive sites, lysine side-chains within $30 \AA$ could be potentially cross-linked.

We performed chemical cross-linking of the 605 complexes prepared with the full-length, domain I or domain I-II of Sdo1p. The CX-MS results show that a predominant cross-linking is between Sdo1p and uL16 through Lys62 (Sdo1p)-Lys184 (uL16) (Figs. 5A, 5B and S5), which is highly consistent with previous data that $u L 16$ is involved in Sdo1p recruitment in the late-stage maturation of the 605 subunit (Sulima et al., 2014a). Another crosslinking was seen between Lys68 of Sdo1p and Lys of uL5 (Fig. S5).

Altogether, these results demonstrate that the interaction of Sdo1p with the 60 S subunit is highly dynamic, which might be essential for its function in probing the conformational status of the ribosomal P-site during the late stage of cytoplasmic maturation of the 605 subunit.

\section{DISCUSSION}

According to the established framework of Sdo1p in the 60S maturation, the function of Sdo1p is, by interacting with 


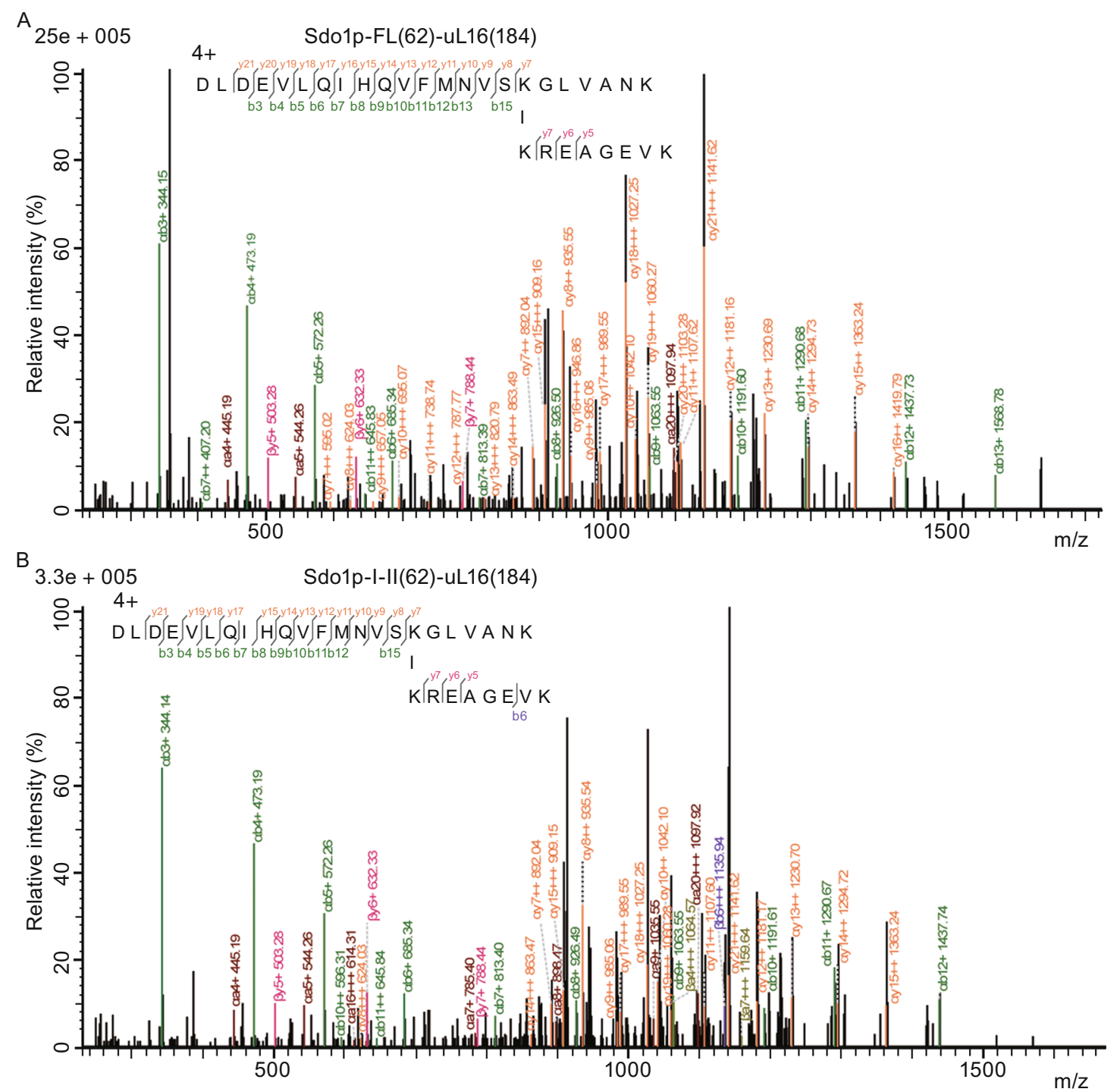

Figure 5. Crosslinking of Sdo1p with uL16 identified in CX-MS. (A) Representative MS spectra of the cross-linked peptides between Sdo1p and uL16 detected in the samples of the 60S-Sdo1p-FL (full-length) complex (A), the 60S-Sdo1p-I-II (Domain I-II) complex (B). Primary sequences of linked peptides are shown, with sites of cleavages labelled in different colors in both the sequences and spectra. $4+$ or $3+$ indicates the charge of the cross-linked peptides.

Efl1p, to promote the release of nucleolar shuttling factor Tif6p (Menne et al., 2007). Domains II-III of SBDS were reported to directly interact with Efl1p (Asano et al., 2014), and it was proposed that Sdo1p/SBDS might act as nucleotide exchange factor to stabilize the binding of GTP to Efl1p (Gijsbers et al., 2013). Because the binding site of Tif6p (Gartmann et al., 2010; Klinge et al., 2011) is rather distant from the binding site of Sdo1p on the 60S subunit, these data have put Sdo1p in a central position of this maturation pathway. Our data show that Sdo1p interacts with the ribosomal P-site (H69) through its domain I, with terminal domain II-III capable of moving around (Fig. 4E), suggesting that the essential role of Sdo1p is to probe the conformational status of the ribosomal P-site (Fig. 6G). Once the correct/native conformation of the ribosomal P-site is established, which in turn stabilizes domain II-III of Sdo1p to induce Tif6p-releasing activity of Efl1p. This hypothesis is further supported by the essential role of uL16 in the maturation of the $60 \mathrm{~S}$ subunit. The $\mathrm{uL} 16$ was also found to cooperate with Sdo1p and Efl1p to release Tif6p, as well as Nmd3 (Bussiere et al., 2012; Hedges et al., 2005; Menne et al., 2007; Sulima et al., 2014a; Sulima et al., 2014b; West et al., 2005). More importantly, uL16 (R98S) mutant in yeast causes a defect in late-stage $60 \mathrm{~S}$ subunit maturation and targets mutant ribosomes for degradation (Sulima et al., 2014b), suggesting a checkpoint role of uL16 in the quality 
A

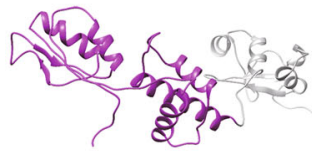

$(60 \mathrm{~S}-\mathrm{Sdo} 1 \mathrm{p})_{2}$

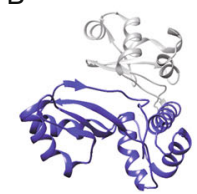

60S-SBDS-Efl1p
C

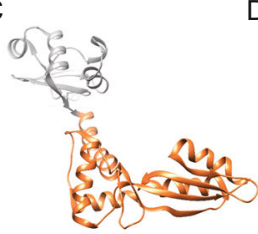

60S-SDBS
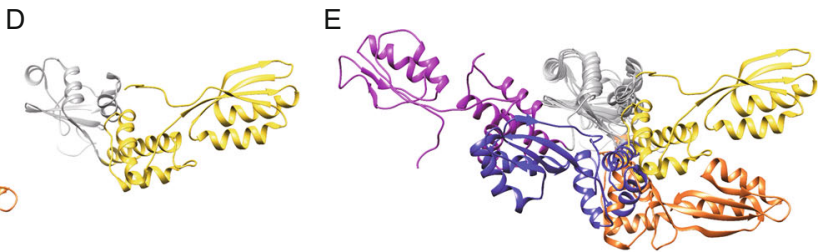
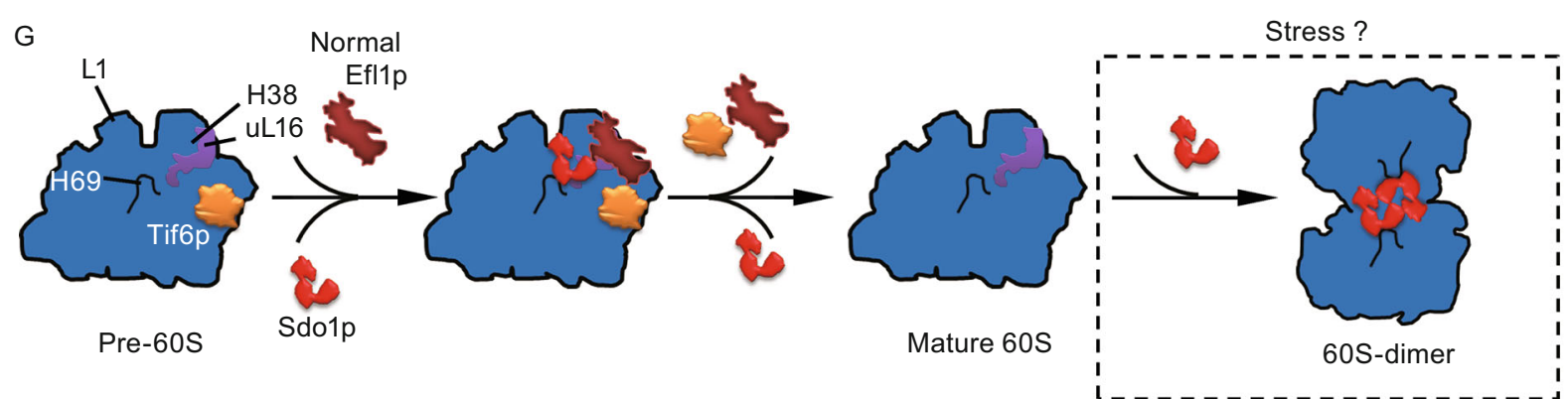

Figure 6. Proposed model of the action of Sdo1p in the late-stage maturation of the $60 \mathrm{~S}$ subunit. (A-E) Conformational states of Sdo1p/SBDS. Coordinates of SBDS in heterologous 60S-SBDS-Efl1p (B) and 60S-SBDS (C) complexes were taken from a very recent cryo-EM work (Weis et al., 2015). One snapshot of NMR structures of human SBDS (D) was taken from a previous study (de Oliveira et al., 2010). All the structures were aligned using the domain I of Sdo1p/SBDS as reference. (G) In normal condition, Sdo1p, as a member of a conformational signal relay system, probes the maturation status of the ribosomal P-site, and passes the signal to Efl1p to release Tif6p from the nearly mature $60 S$ subunit. Under a certain stress, Sdo1p might induce the formation of inactive $60 S$ dimers to limit the cellular translation capacity.

control of the 60S maturation (Sulima et al., 2014a). Our CXMS data indicate that Sdo1p (domain I) is in close contact with uL16. Taking into consideration of the critical role of the P-site loop of UL16 in Sdo1p binding (Sulima et al., 2014a) and Tif6p release (Bussiere et al., 2012), it is plausible that Sdo1p senses the incorporation and conformational maturation of $\mathrm{UL} 16$ on the $60 \mathrm{~S}$ subunit and pass the signal to Efl1p. Also, our structural data reveal that $\mathrm{H} 69$ and $\mathrm{H} 38$ are two binding partners of Sdo1p, both of which are highly conserved (structurally and functionally) in eukaryotes and prokaryotes. And these two helices are known to be highly dynamic and adopt very different conformations in the pre$60 S$ (yeast) (Bradatsch et al., 2012; Greber et al., 2012; Leidig et al., 2014) or pre-50S (bacterial) (Jomaa et al., 2014; Li et al., 2013; Zhang et al., 2014a) particles. Taken together, our data support a conformational signal relay system for these factors (uL16-Sdo1p-Efl1p-Tif6p), in which Sdol1p and Efl1p couple two spatially distant events during the latestage maturation of the $60 \mathrm{~S}$ subunit, the ribosomal P-site maturation and the release of anti-association factor Tif6p (Gartmann et al., 2010). The dynamic nature of Sdo1p on the $60 S$ subunit ensures its participation as a probing factor to sense the conformational maturation of its surrounding rRNA and RP.

Our structural data suggest that Sdo1p remains very dynamic on the 60S subunit. Very interestingly, in comparison with the very recent data on chimerical 60S-SBDS and
60S-SBDS-Efl1p (Weis et al., 2015), domains II-III of Sdo1p/ SBDS could adopt very different conformations on the 605 subunit (Fig. 6A-E). These observations are consistent with the NMR spectroscopic analysis of SBDS in solution (de Oliveira et al., 2010). Altogether, these results support our hypothesis that $\mathrm{Sdo} 1 \mathrm{p}$ is a dynamic probe of the maturation status of the 60S subunit, and the inter-domain flexibility of Sdo1p/SBDS is essential for its function.

Our CX-MS data also indicate a proximity for UL5 and Sdo1p. This observation might be of physiological significance to the disease of SDS in human. It was generally believed that partial loss of SBDS function in SDS might induce a nucleolar stress from defective ribosome biogenesis and activate the RP (ribosomal protein)-p53-HDM2 pathway, and uL5 (RPL11) is one of RPs involved in stabilizing p53 following nucleolar stress (Deisenroth and Zhang, 2010; Holmberg Olausson et al., 2012; Nakhoul et al., 2014).

In the present work, we found that Sdo1p could induce the formation of 60S-60S dimers in vitro through crosslinking $\mathrm{H} 69$ and $\mathrm{H} 38$ from the two participating $60 \mathrm{~S}$ subunits. In bacterial and mammalian cells, it was shown that higherorder organization of ribosomes is employed by the cells as a means to regulate the translation capacity by limiting the number of active ribosomes. In E. coli, upon transition to stationary phase, cells start to accumulate $100 \mathrm{~S}$ particles (Yoshida and Wada, 2014), composed of 70 S dimers induced by protein factors called ribosome modulation factor 
(RMF) (Wada et al., 1995) and hibernation promoting factor (HPF) (Ueta et al., 2005). When mammalian (rat) cells were challenged by amino acid starvation, a form of $110 \mathrm{~S}$ particles, including 805 dimers and 80S-60S heterodimers, were also detected (Krokowski et al., 2011). These previous data indicate a conserved mechanism of translation modulation by organizing ribosomes into resting higher-order assemblies. Previous work also suggested SBDS has a second role in multiple cellular stress response pathways, independent of its primary role in ribosome biogenesis (Ball et al., 2009). HEK293 cells with the deletion of SBDS are hypersensitive to DNA damage and endoplasmic reticulum stress (Ball et al., 2009). HeLa cells with SBDS-knockdown, as well as SDS patient cells are hypersensitive to Fas-mediated apoptosis (Watanabe et al., 2009; Watanabe and Dror, 2005). In yeast, Sdo1p physically interacts with Btn1p (CLN3 in human) and was suggested to involved in cellular responses to $\mathrm{pH}$ and nutrient changes (Vitiello et al., 2010). Therefore, it is possible that the $60 \mathrm{~S}$ dimers induced by Sdo1p, if not an in vitro artifact, might represent a form of inactive storage of ribosomal subunits upon a certain stress (Fig. 6G). This attractive hypothesis merits further investigation.

\section{MATERIALS AND METHODS}

Gene cloning and protein purification

The genes encoding full-length and truncated Sdo1p were amplified using standard Polymerase Chain Reaction (PCR) from S. cerevisiae. Primers were designed according to respective domains of yeast Sdo1p to clone the full-length (1-250), domain I (1-95), domain II (96-169), domain III (170-250), domain I-II (1-169) and domain II-III (96-250) constructs. The fragments were cloned into $\mathrm{pET} 21 \mathrm{~b}$ vector to yield $\mathrm{pET} 21 \mathrm{~b}-\mathrm{Sdo} 1 \mathrm{p}$ constructs with C-terminal $6 \times$-His-tag for purification. The plasmids were transformed into E. coli BL21 (DE3) cells for overexpression.

For protein purification, cells were cultured in LB media containing $50 \mu \mathrm{g} / \mathrm{mL}$ of ampicillin at $30^{\circ} \mathrm{C}$ to an $\mathrm{OD}_{600}$ of 1.0 and induced by $0.5 \mathrm{mmol} / \mathrm{L} \mathrm{IPTG}$ for $4 \mathrm{~h}$. Cells were pelleted and suspended in buffer A (50 mmol/L Tris- $\mathrm{HCl}$ [pH 7.5], $500 \mathrm{mmol} / \mathrm{L} \mathrm{NaCl}, 1 \mathrm{mmol} / \mathrm{L}$ $\mathrm{PMSF}$ ) containing $30 \mathrm{mmol} / \mathrm{L}$ imidazole and disrupted by an ultrasonic processor. Cell lysates were clarified by centrifugation at 13,000 rpm (Avanti J-26 XP, JA25.50 rotor, Beckman Coulter) for $1 \mathrm{~h}$. The clarified lysates were load onto a Ni-NTA column (GE Healthcare) and eluted with buffer B (same as buffer A but containing $500 \mathrm{mmol} / \mathrm{L}$ imidazole). The target proteins were pooled, concentrated with Millipore Amicon Ultra Centrifugal filters and subjected to gel filtration chromatography (Superdex75 10/300 GL, GE Healthcare) with buffer C (25 mmol/L Tris- $\mathrm{HCl}$ [pH7.5], $100 \mathrm{mmol} / \mathrm{L} \mathrm{KCl}, 2.5 \mathrm{mmol} / \mathrm{L} \mathrm{MgCl}_{2}$ ). Purified proteins were split into aliquots and stored at $-80^{\circ} \mathrm{C}$.

\section{Ribosomal subunit purification}

Yeast cells (S. cerevisiae S288C) were grown in $3 \mathrm{~L}$ of YEPD (1\% yeast extract, $2 \%$ Bacto peptone and $2 \%$ glucose) medium to an
$\mathrm{OD}_{600}$ of 1.0. Ribosome purification was carried out as previously described (Zhang et al., 2014b). Cells were harvested and washed twice with ice-cold Lysis buffer $(50 \mathrm{mmol} / \mathrm{L}$ Tris-acetate $[\mathrm{pH} 7.0]$, $50 \mathrm{mmol} / \mathrm{L} \mathrm{NH}{ }_{4} \mathrm{Cl}, 12 \mathrm{mmol} / \mathrm{L} \mathrm{MgCl}_{2}, 1 \mathrm{mmol} / \mathrm{L} \mathrm{DTT}, 1 \mathrm{pill} / 50-\mathrm{mL}$ complete protease inhibitor cocktail [Roche]). Resuspended cells were disrupted with a high-pressure homogenizer (5000 p.s.i.) for three times. Cell lysates were centrifuged at $13,000 \mathrm{rpm}$ for $1 \mathrm{~h}$ at $4^{\circ} \mathrm{C}$ in a JA 25.50 motor (Beckman Coulter). Supernatants were layered over a $10 \%-50 \%$ linear sucrose gradient $(50 \mathrm{mmol} / \mathrm{L}$ Trisacetate [pH 7.0], $100 \mathrm{mmol} / \mathrm{L} \mathrm{NH} \mathrm{NCl}_{4}, 12 \mathrm{mmol} / \mathrm{L} \mathrm{MgCl} 2,1 \mathrm{mmol} / \mathrm{L}$ DTT), and centrifuged at $30,000 \mathrm{rpm}$ for $5 \mathrm{~h}$ in an SW32 rotor (Beckman Coulter) at $4^{\circ} \mathrm{C}$. The gradient profile was monitored at 254-nm wavelength and fractionated in a gradient collector (Teledyne Isco). Fractions of $80 \mathrm{~S}$ ribosomes were collected, concentrated with Amicon Ultra Centrifugal filters (Millipore) and washed with separation buffer $(50 \mathrm{mmol} / \mathrm{L}$ Tris- $\mathrm{HCl}[\mathrm{pH} 7.4], 500 \mathrm{mmol} / \mathrm{L} \mathrm{KCl}$, $2.5 \mathrm{mmol} / \mathrm{L} \mathrm{MgCl}, 1 \mathrm{mmol} / \mathrm{L} \mathrm{DTT})$. After the buffer was changed to separation buffer, the mixture was incubated at $37^{\circ} \mathrm{C}$ for $10 \mathrm{~min}$. Reaction mixtures were layered over a $10 \%-40 \%$ linear sucrose gradient $(50 \mathrm{mmol} / \mathrm{L}$ Tris- $\mathrm{HCl}[\mathrm{pH} 7.4], 500 \mathrm{mmol} / \mathrm{L} \mathrm{KCl}, 2.5 \mathrm{mmol} / \mathrm{L}$ $\mathrm{MgCl}_{2}, 1 \mathrm{mmol} / \mathrm{L}$ DTT) and centrifuged at 30,000 rpm in an SW32 rotor (Beckman Coulter) at $4^{\circ} \mathrm{C}$ for $7 \mathrm{~h}$. The gradient was similar analyzed and fractions of $40 \mathrm{~S}$ and $60 \mathrm{~S}$ subunits were separately collected. After concentrating with Millipore Amicon Ultra Centrifugal filters, samples were split into aliquots and stored at $-80^{\circ} \mathrm{C}$ for further use.

In vitro binding with gel filtration

The $60 \mathrm{~S}$ subunit $(150 \mathrm{pmol})$ and full-length Sdo1p (20-fold excess) were mixed in 500- $\mu \mathrm{L}$ buffer $\mathrm{C}(25 \mathrm{mmol} / \mathrm{L}$ Tris- $\mathrm{HCl}[\mathrm{pH} 7.5]$, $100 \mathrm{mmol} / \mathrm{L} \mathrm{KCl}, 2.5 \mathrm{mmol} / \mathrm{L} \mathrm{MgCl}_{2}$ ), and incubated at $30^{\circ} \mathrm{C}$ for $15 \mathrm{~min}$. The mixture was loaded onto a gel filtration column (Superose6 10/300 GL, GE Healthcare). The peak fractions were subjected to SDS-PAGE.

\section{Co-sedimentation assay}

$60 S$ ribosomal subunits $50 \mathrm{pmol}$ ) were incubated with full-length or truncated Sdo1p proteins in a ratio of $1: 20$ for $15 \mathrm{~min}$ at $30^{\circ} \mathrm{C}$ in $90 \mu \mathrm{L}$ buffer. The mixtures were then loaded onto a sucrose cushion (25 mmol/L Tris- $\mathrm{HCl}$ [pH 7.5], $100 \mathrm{mmol} / \mathrm{L} \mathrm{KCl,} 2.5 \mathrm{mmol} / \mathrm{L} \mathrm{MgCl}_{2}$, $33 \%$ sucrose) and centrifuged at 95,000 rpm for $2 \mathrm{~h}$ in a TLA-100 rotor (Beckman Coulter) at $4^{\circ} \mathrm{C}$. The supernatants $(1 / 18)$ and the pellets $(1 / 3)$ were collected separately and resolved by Tricine-SDSPAGE.

\section{Sucrose density gradient centrifugation (SDGC)}

Samples of ribosomes and Sdo1p variants were changed to a Hepes-KOH buffer system (25 mmol/L Hepes-KOH [pH7.5], $100 \mathrm{mmol} / \mathrm{L} \mathrm{KCl}, 2.5 \mathrm{mmol} / \mathrm{L} \mathrm{MgCl}_{2}$ ). $37.5 \mathrm{pmol}$ ribosomes (40S, $60 \mathrm{~S}$ or $80 \mathrm{~S}$ ) were incubated with full-length or truncated Sdo1p proteins in a ratio of $1: 20$ for $15 \mathrm{~min}$ at $30^{\circ} \mathrm{C}$ in $200 \mu \mathrm{L}$ buffer. The mixtures were incubated with or without $0.1 \%$ glutaraldehyde for another $15 \mathrm{~min}$, layered onto a 10\%-50\% linear sucrose gradient (25 mmol/L Hepes-KOH [pH 7.5], $100 \mathrm{mmol} / \mathrm{L} \mathrm{KCl,} 2.5 \mathrm{mmol} / \mathrm{L}$ $\mathrm{MgCl}_{2}$ ), and centrifuged at $39,000 \mathrm{rpm}$ for $4 \mathrm{~h}$ in an SW41 rotor 
(Beckman Coulter) at $4^{\circ} \mathrm{C}$. The gradient was analyzed and fractionated in an ISCO gradient collector.

\section{In vitro binding with Bio-layer Interferometry}

The BLI-based experiments were performed with Octet RED96 System (ForteBio, Pall Corp.) according to the manufacturer's instructions. Sdo1p variants (wild type and mutants) in Hepes- $\mathrm{KOH}$ buffer system (25 mmol/L Hepes-KOH [pH 7.5], $100 \mathrm{mmol} / \mathrm{L} \mathrm{KCl}$, $2.5 \mathrm{mmol} / \mathrm{L} \mathrm{MgCl}_{2}$ ) were immobilized to the optic biosensors of AntiPenta-HIS (HIS1 K, ForteBio). Before each experiment, biosensors were pre-equilibrated with binding buffer, followed by equilibrium binding with Sdo1p variants $(2 \mu \mathrm{g} / \mathrm{mL})$. Pre-experiments were carried to determine the optimal concentration range of the $60 \mathrm{~S}$ subunit suitable for the measurements. For the single concentration experiments, a final concentration of $48 \mathrm{nmol} / \mathrm{L} 60 \mathrm{~S}$ subunit was used. For the concentration gradient experiments, 2-fold dilution series of the $60 \mathrm{~S}$ subunit were used $(48 \mathrm{nmol} / \mathrm{L}, 24 \mathrm{nmol} / \mathrm{L}, 12 \mathrm{nmol} / \mathrm{L}, 6 \mathrm{nmol} / \mathrm{L}$, $3 \mathrm{nmol} / \mathrm{L}$, and $1.75 \mathrm{nmol} / \mathrm{L}$ ). Both the association and dissociation of each measurement were carried out for $240 \mathrm{~s}$. The data was analyzed and dissociation constants were calculated by the software of the Data analysis 7.0 provided by ForteBio.

\section{Cryo-sample preparation and data collection}

The $60 \mathrm{~S}$ subunit $(100 \mathrm{nmol} / \mathrm{L})$ was incubated with 20 -fold or 10 -fold excess of full-length $\mathrm{Sdo} 1 \mathrm{p}$ at $30^{\circ} \mathrm{C}$ for $15 \mathrm{~min}$. The mixture was diluted to a final concentration of $60 \mathrm{nmol} / \mathrm{L}$ for the $60 \mathrm{~S}$ complex in binding buffer. $4-\mu \mathrm{L}$ aliquots of samples were applied to $300-$ mesh 2/2 glow-discharged Quantifoil grids (Quantifoil Micro Tools) which were pre-coated with a thin layer of carbon. The grids were blotted and plunged into liquid ethane with an FEI Mark IV Vitrobot operated at $4^{\circ} \mathrm{C}$. For the sample of dimeric $60 \mathrm{~S}-\mathrm{Sdo} 1 \mathrm{p}$ complexes (20-fold excess of Sdo1p), data collection was performed with an FEI F20 at $80,000 \times$ magnification with a Gatan UltraScan 4000 CCD camera. For the sample of monomeric 60S-Sdo1p complexes, data collection was done with an FEI Titan Krios equipped with an FEI Eagle $4 \mathrm{~K} \times 4 \mathrm{~K} \mathrm{CCD}$ camera at 75,000 $\times$ magnification. All the images were recorded under low-dose conditions $\left(\sim 20\right.$ e- $\left./ \AA^{2}\right)$ with AutoEMation package (Lei and Frank, 2005).

\section{Image processing and structural analysis}

Micrograph screening, estimation of contrast transfer function parameters, and initial particle picking were performed with SPIDER package (Shaikh et al., 2008). An artificial 60S dimer was used as the template for automatic particle picking (Rath and Frank, 2004). For 60S-Sdo1p dimers, 116,271 particles (from 3,294 micrographs) (2.76 A/pixel with a binning factor of two) were picked and subjected reference-free 2D classification using XMIPP (Scheres et al., 2008), EMAN2 (Tang et al., 2007) and RELION (Scheres, 2012) packages, which rendered essentially similar results with many of the dimers displaying considerable flexibility on the orientation of the two 605 subunits. For the $3 \mathrm{D}$ classification, all the particles were classified into 6 classes without or with C2 symmetry imposed using RELION package. For $\mathrm{C} 2$-imposed classification, two classes display reliable details for both two $60 \mathrm{~S}$ subunits were combined $(30,452$ particles) and subject to another round of 3D classification. The second round was done without imposing the C2-symmetry, resulting into 4 classes. Two of them were combined (13,219 in total) and subjected to structural refinement by RELION. The final resolution of the refined map is $14 \AA$ based on the 0.143 cutoff criteria of the gold-standard Fourier shell correlation (FSC).

For monomeric 60S-Sdo1p complexes, 305,371 particles (2.33 A/pixel with a binning factor of two) (from 7,994 micrographs) were classified into 10 classes using RELION. One class $(40,186$ particles) displayed substantial additional density at the ribosomal $\mathrm{P}$-site. After structural refinement, the final reported resolution is $9 \AA$ based on the 0.143 cutoff criteria of the gold-standard FSC.

The yeast homology model of Sdo1p was modelled using I-TASSER (Roy et al., 2010). The fitting of two copies of Sdo1p was done manually using UCSF Chimera (Pettersen et al., 2004), and optimized by the "fit in map" module of Chimera. Coordinates of the yeast ribosome were from a previous crystallography study (BenShem et al., 2011).

\section{Cross-linking mass spectrometry analysis (CX-MS)}

50 pmol 605 ribosome was incubated with full-length or truncated Sdo1p at 1:20 molar ratio for $15 \mathrm{~min}$ at $30^{\circ} \mathrm{C}(25 \mathrm{mmol} / \mathrm{L}$ Hepes- $\mathrm{KOH}$ [pH 7.5], $100 \mathrm{mmol} / \mathrm{L} \mathrm{KCl}, 2.5 \mathrm{mmol} / \mathrm{L} \mathrm{MgCl}_{2}$ ). The mixture was cross-linked with DSS or BS3 (Thermo Fisher Scientific) at 1:1 mass ratio at room temperature for $1 \mathrm{~h}$. The reaction was then quenched with $20 \mathrm{mmol} / \mathrm{L}$ ammonium bicarbonate. Cross-linking products were analyzed by SDS-PAGE to evaluate the cross-linking efficiency. For MS analysis, proteins were precipitated with acetone, resuspended in $8 \mathrm{~mol} / \mathrm{L}$ urea, $100 \mathrm{mmol} / \mathrm{L}$ Tris, $\mathrm{pH} 8.5$, and digested with trypsin. LC-MS/MS analyses were carried on an EASY-nLC 1000 system (Thermo Fisher Scientific) interfaced with a Q-Exactive mass spectrometer (Thermo Fisher Scientific). Peptides were separated on an analytical capillary column $(75 \mu \mathrm{m} \times 10 \mathrm{~cm}, 1.8 \mu \mathrm{m} \mathrm{C18})$ using a $60 \mathrm{~min}$ linear gradient at a flow rate of $200 \mathrm{~nL} / \mathrm{min}$. The mass spectrometer was operated in data-dependent mode with one full MS scan followed by ten HCD MS/MS scans with a dynamic exclusion time of $30 \mathrm{~s}$. Precursors of the $+1,+2$, or unassigned charge states were rejected. pLink (Yang et al., 2012) was used for identification of cross-linked peptides by requiring FDR $<5 \%$.

\section{ACCESSION CODE}

The density map of the 60S-Sdo1p dimer has been deposited in the EMdataBank under accession codes of EMD-3280.

\section{ACKNOWLEDGMENTS}

We acknowledge the China National Center for Protein Sciences (Beijing) and the "Explorer 100" cluster system of Tsinghua National Laboratory for Information Science and Technology for providing computation resource. This work was supported by grants from the National Natural Science Foundation of China (Grant Nos. 31422016 and 31470722 to N.G.), the National Basic Research Program (973 Program) (No. 2013CB910404 to N.G.), Beijing Higher Education Young Elite Teacher Project (YETP0131 to N.G.), and Tsinghua University (20131089278 to N.G.). 


\section{COMPLIANCE WITH ETHICS GUIDELINES}

Chengying Ma, Kaige Yan, Dan Tan, Ningning Li, Yixiao Zhang, Yi Yuan, Zhifei Li, Meng-Qiu Dong, Jianlin Lei, and Ning Gao declare no conflict of interest.

This article does not contain any studies with human or animal subjects performed by the any of the authors.

\section{AUTHOR CONTRIBUTION}

NG., J.L. and C.M. conceived and designed the project. C.M., K.Y., N.L., Y.Z., Y.Y., and Z.L. performed experiments. D.T. and M-Q.D. performed CXMS. C.M. and N.G. wrote the paper.

\section{OPEN ACCESS}

This article is distributed under the terms of the Creative Commons Attribution 4.0 International License (http://creativecommons.org/ licenses/by/4.0/), which permits unrestricted use, distribution, and reproduction in any medium, provided you give appropriate credit to the original author(s) and the source, provide a link to the Creative Commons license, and indicate if changes were made.

\section{REFERENCES}

Asano N, Atsuumi H, Nakamura A, Tanaka Y, Tanaka I, Yao M (2014) Direct interaction between EFL1 and SBDS is mediated by an intrinsically disordered insertion domain. Biochem Biophys Res Commun 443:1251-1256

Austin KM, Leary RJ, Shimamura A (2005) The shwachmandiamond SBDS protein localizes to the nucleolus. Blood 106:1253-1258

Ball HL, Zhang B, Riches JJ, Gandhi R, Li J, Rommens JM, Myers JS (2009) Shwachman-Bodian diamond syndrome is a multifunctional protein implicated in cellular stress responses. Hum Mol Genet 18:3684-3695

Ben-Shem A, Garreau de Loubresse N, Melnikov S, Jenner L, Yusupova G, Yusupov M (2011) The structure of the eukaryotic ribosome at 3.0 a resolution. Science 334:1524-1529

Bernstein KA, Bleichert F, Bean JM, Cross FR, Baserga SJ (2007) Ribosome biogenesis is sensed at the start cell cycle checkpoint. Mol Biol Cell 18:953-964

Boocock GR, Morrison JA, Popovic M, Richards N, Ellis L, Durie PR, Rommens JM (2003) Mutations in SBDS are associated with Shwachman-Diamond syndrome. Nat Genet 33:97-101

Boocock GR, Marit MR, Rommens JM (2006) Phylogeny, sequence conservation, and functional complementation of the SBDS protein family. Genomics 87:758-771

Boulon S, Westman BJ, Hutten S, Boisvert FM, Lamond AI (2010) The nucleolus under stress. Mol Cell 40:216-227

Bradatsch B, Leidig C, Granneman S, Gnadig M, Tollervey D, Bottcher B, Beckmann R, Hurt E (2012) Structure of the pre-60S ribosomal subunit with nuclear export factor Arx1 bound at the exit tunnel. Nat Struct Mol Biol 19:1234-1241
Burwick N, Coats SA, Nakamura T, Shimamura A (2012) Impaired ribosomal subunit association in Shwachman-Diamond syndrome. Blood 120:5143-5152

Bussiere C, Hashem Y, Arora S, Frank J, Johnson AW (2012) Integrity of the P-site is probed during maturation of the $60 \mathrm{~S}$ ribosomal subunit. J Cell Biol 197:747-759

Chakraborty A, Uechi T, Kenmochi N (2011) Guarding the 'translation apparatus': defective ribosome biogenesis and the p53 signaling pathway. Wiley interdiscip Rev RNA 2:507-522

de Oliveira JF, Sforca ML, Blumenschein TM, Goldfeder MB, Guimaraes BG, Oliveira CC, Zanchin NI, Zeri AC (2010) Structure, dynamics, and RNA interaction analysis of the human SBDS protein. J Mol Biol 396:1053-1069

Deisenroth C, Zhang Y (2010) Ribosome biogenesis surveillance: probing the ribosomal protein-Mdm2-p53 pathway. Oncogene 29:4253-4260

Dez C, Tollervey D (2004) Ribosome synthesis meets the cell cycle. Curr Opin Microbiol 7:631-637

Finch AJ, Hilcenko C, Basse N, Drynan LF, Goyenechea B, Menne TF, Gonzalez Fernandez A, Simpson P, D'Santos CS, Arends MJ et al (2011) Uncoupling of GTP hydrolysis from elF6 release on the ribosome causes Shwachman-Diamond syndrome. Genes Dev 25:917-929

Freed EF, Bleichert F, Dutca LM, Baserga SJ (2010) When ribosomes go bad: diseases of ribosome biogenesis. Mol BioSyst 6:481-493

Gamalinda M, Ohmayer U, Jakovljevic J, Kumcuoglu B, Woolford J, Mbom B, Lin L, Woolford JL Jr (2014) A hierarchical model for assembly of eukaryotic 605 ribosomal subunit domains. Genes Dev 28:198-210

Ganapathi KA, Austin KM, Lee CS, Dias A, Malsch MM, Reed R, Shimamura A (2007) The human Shwachman-Diamond syndrome protein, SBDS, associates with ribosomal RNA. Blood 110:1458-1465

Gartmann M, Blau M, Armache JP, Mielke T, Topf M, Beckmann R (2010) Mechanism of elF6-mediated inhibition of ribosomal subunit joining. J Biol Chem 285:14848-14851

Gijsbers A, Garcia-Marquez A, Luviano A, Sanchez-Puig N (2013) Guanine nucleotide exchange in the ribosomal GTPase EFL1 is modulated by the protein mutated in the Shwachman-Diamond syndrome. Biochem Biophys Res Commun 437:349-354

Greber BJ, Boehringer D, Montellese C, Ban N (2012) Cryo-EM structures of Arx1 and maturation factors Rei1 and Jjj1 bound to the 60S ribosomal subunit. Nat Struct Mol Biol 19:1228-1233

Hedges J, West M, Johnson AW (2005) Release of the export adapter, Nmd3p, from the 60S ribosomal subunit requires Rpl10p and the cytoplasmic GTPase Lsg1p. Embo J 24:567-579

Holmberg Olausson K, Nister M, Lindstrom MS (2012) p53 -dependent and -independent nucleolar stress responses. Cells 1:774-798

Jomaa A, Jain N, Davis JH, Williamson JR, Britton RA, Ortega J (2014) Functional domains of the $50 \mathrm{~S}$ subunit mature late in the assembly process. Nucl Acids Res 42:3419-3435

Jorgensen P, Nishikawa JL, Breitkreutz BJ, Tyers M (2002) Systematic identification of pathways that couple cell growth and division in yeast. Science 297:395-400

Karbstein K (2013) Quality control mechanisms during ribosome maturation. Trends Cell Biol 23:242-250 
Klinge S, Voigts-Hoffmann F, Leibundgut M, Arpagaus S, Ban N (2011) Crystal structure of the eukaryotic 605 ribosomal subunit in complex with initiation factor 6. Science 334:941-948

Krokowski D, Gaccioli F, Majumder M, Mullins MR, Yuan CL, Papadopoulou B, Merrick WC, Komar AA, Taylor D, Hatzoglou M (2011) Characterization of hibernating ribosomes in mammalian cells. Cell Cycle 10:2691-2702

Lebaron S, Schneider C, van Nues RW, Swiatkowska A, Walsh D, Bottcher B, Granneman S, Watkins NJ, Tollervey D (2012) Proofreading of pre-40S ribosome maturation by a translation initiation factor and 60 S subunits. Nat Struct Mol Biol 19:744-753

Lei J, Frank J (2005) Automated acquisition of cryo-electron micrographs for single particle reconstruction on an FEI Tecnai electron microscope. J Struct Biol 150:69-80

Leidig C, Thoms M, Holdermann I, Bradatsch B, Berninghausen O, Bange G, Sinning I, Hurt E, Beckmann R (2014) 60 S ribosome biogenesis requires rotation of the $5 \mathrm{~S}$ ribonucleoprotein particle. Nat Commun 5:3491

Li N, Chen Y, Guo Q, Zhang Y, Yuan Y, Ma C, Deng H, Lei J, Gao N (2013) Cryo-EM structures of the late-stage assembly intermediates of the bacterial $50 \mathrm{~S}$ ribosomal subunit. Nucl Acids Res 41:7073-7083

Lo KY, Li Z, Bussiere C, Bresson S, Marcotte EM, Johnson AW (2010) Defining the pathway of cytoplasmic maturation of the $60 \mathrm{~S}$ ribosomal subunit. Mol Cell 39:196-208

Luz JS, Georg RC, Gomes CH, Machado-Santelli GM, Oliveira CC (2009) Sdo1p, the yeast orthologue of Shwachman-BodianDiamond syndrome protein, binds RNA and interacts with nuclear rRNA-processing factors. Yeast 26:287-298

Matsuo Y, Granneman S, Thoms M, Manikas RG, Tollervey D, Hurt E (2014) Coupled GTPase and remodelling ATPase activities form a checkpoint for ribosome export. Nature 505:112-116

Menne TF, Goyenechea B, Sanchez-Puig N, Wong CC, Tonkin LM, Ancliff PJ, Brost RL, Costanzo M, Boone C, Warren AJ (2007) The Shwachman-Bodian-Diamond syndrome protein mediates translational activation of ribosomes in yeast. Nat Genet 39:486-495

Miluzio A, Beugnet A, Volta V, Biffo S (2009) Eukaryotic initiation factor 6 mediates a continuum between $60 \mathrm{~S}$ ribosome biogenesis and translation. EMBO Rep 10:459-465

Montanaro L, Trere D, Derenzini M (2008) Nucleolus, ribosomes, and cancer. Am J Pathol 173:301-310

Moore JBT, Farrar JE, Arceci RJ, Liu JM, Ellis SR (2010) Distinct ribosome maturation defects in yeast models of DiamondBlackfan anemia and Shwachman-Diamond syndrome. Haematologica 95:57-64

Nakhoul H, Ke J, Zhou X, Liao W, Zeng SX, Lu H (2014) Ribosomopathies: mechanisms of disease. Clin Med Insights Blood Disorders 7:7-16

Narla A, Ebert BL (2010) Ribosomopathies: human disorders of ribosome dysfunction. Blood 115:3196-3205

$\mathrm{Ng} \mathrm{CL}$, Waterman DG, Koonin EV, Walters AD, Chong JP, Isupov MN, Lebedev AA, Bunka DH, Stockley PG, Ortiz-Lombardia M et al (2009) Conformational flexibility and molecular interactions of an archaeal homologue of the Shwachman-Bodian-Diamond syndrome protein. BMC Struct Biol 9:32

Panse VG, Johnson AW (2010) Maturation of eukaryotic ribosomes: acquisition of functionality. Trends Biochem Sci 35:260-266
Pettersen EF, Goddard TD, Huang CC, Couch GS, Greenblatt DM, Meng EC, Ferrin TE (2004) UCSF Chimera-a visualization system for exploratory research and analysis. J Comput Chem 25:1605-1612

Rath BK, Frank J (2004) Fast automatic particle picking from cryoelectron micrographs using a locally normalized cross-correlation function: a case study. J Struct Biol 145:84-90

Roy A, Kucukural A, Zhang Y (2010) I-TASSER: a unified platform for automated protein structure and function prediction. Nat Protoc 5:725-738

Ruggero D, Pandolfi PP (2003) Does the ribosome translate cancer? Nat Rev Cancer 3:179-192

Savchenko A, Krogan N, Cort JR, Evdokimova E, Lew JM, Yee AA, Sanchez-Pulido L, Andrade MA, Bochkarev A, Watson JD et al (2005) The Shwachman-Bodian-Diamond syndrome protein family is involved in RNA metabolism. J Biol Chem 280:1921319220

Scheres SHW (2012) RELION: implementation of a Bayesian approach to cryo-EM structure determination. J Struct Biol 180:519-530

Scheres SHW, Nunez-Ramirez R, Sorzano COS, Carazo JM, Marabini R (2008) Image processing for electron microscopy single-particle analysis using XMIPP. Nat Protoc 3:977-990

Shaikh TR, Gao H, Baxter WT, Asturias FJ, Boisset N, Leith A, Frank $J$ (2008) SPIDER image processing for single-particle reconstruction of biological macromolecules from electron micrographs. Nat Protoc 3:1941-1974

Shammas C, Menne TF, Hilcenko C, Michell SR, Goyenechea B, Boocock GR, Durie PR, Rommens JM, Warren AJ (2005) Structural and mutational analysis of the SBDS protein family. Insight into the leukemia-associated Shwachman-Diamond Syndrome. J Biol Chem 280:19221-19229

Singh P, Panchaud A, Goodlett DR (2010) Chemical cross-linking and mass spectrometry as a low-resolution protein structure determination technique. Anal Chem 82:2636-2642

Soudet J, Gelugne JP, Belhabich-Baumas K, Caizergues-Ferrer M, Mougin A (2010) Immature small ribosomal subunits can engage in translation initiation in Saccharomyces cerevisiae. EMBO J 29:80-92

Strunk BS, Novak MN, Young CL, Karbstein K (2012) A translationlike cycle is a quality control checkpoint for maturing $40 \mathrm{~S}$ ribosome subunits. Cell 150:111-121

Sulima SO, Gulay SP, Anjos M, Patchett S, Meskauskas A, Johnson AW, Dinman JD (2014a) Eukaryotic rpL10 drives ribosomal rotation. Nucl Acids Res 42:2049-2063

Sulima SO, Patchett S, Advani VM, De Keersmaecker K, Johnson AW, Dinman JD (2014b) Bypass of the pre-60S ribosomal quality control as a pathway to oncogenesis. Proc Natl Acad Sci USA 111:5640-5645

Tang G, Peng L, Baldwin PR, Mann DS, Jiang W, Rees I, Ludtke SJ (2007) EMAN2: An extensible image processing suite for electron microscopy. J Struct Biol 157:38-46

Teng T, Thomas G, Mercer CA (2013) Growth control and ribosomopathies. Curr Opin Genet Dev 23:63-71

Ueta M, Yoshida H, Wada C, Baba T, Mori H, Wada A (2005) Ribosome binding proteins $\mathrm{YhbH}$ and $\mathrm{YfiA}$ have opposite functions during $100 \mathrm{~S}$ formation in the stationary phase of Escherichia coli. Genes Cells 10:1103-1112 
Vitiello SP, Benedict JW, Padilla-Lopez S, Pearce DA (2010) Interaction between Sdo1p and Btn1p in the Saccharomyces cerevisiae model for Batten disease. Hum Mol Genet 19:931-942

Wada A, Igarashi K, Yoshimura S, Aimoto S, Ishihama A (1995) Ribosome modulation factor: stationary growth phase-specific inhibitor of ribosome functions from Escherichia coli. Biochem Biophys Res Commun 214:410-417

Watanabe KI, Dror Y (2005) Characterization of siRNA-mediated SBDS-knockdown cells: Specific hypersensitivity to Fas stimulation. Blood 106:116a

Watanabe K, Ambekar C, Wang H, Ciccolini A, Schimmer AD, Dror $Y$ (2009) SBDS-deficiency results in specific hypersensitivity to Fas stimulation and accumulation of Fas at the plasma membrane. Apoptosis 14:77-89

Weis F, Giudice E, Churcher M, Jin L, Hilcenko C, Wong CC, Traynor D, Kay RR, Warren AJ (2015) Mechanism of elF6 release from the nascent $60 \mathrm{~S}$ ribosomal subunit. Nat Struct Mol Biol 22:914-919

West M, Hedges JB, Chen A, Johnson AW (2005) Defining the order in which $\mathrm{Nmd} 3 \mathrm{p}$ and Rpl10p load onto nascent 60 S ribosomal subunits. Mol Cell Biol 25:3802-3813
Wong CC, Traynor D, Basse N, Kay RR, Warren AJ (2011) Defective ribosome assembly in Shwachman-Diamond syndrome. Blood 118:4305-4312

Woolford JL Jr, Baserga SJ (2013) Ribosome biogenesis in the yeast Saccharomyces cerevisiae. Genetics 195:643-681

Yang B, Wu YJ, Zhu M, Fan SB, Lin J, Zhang K, Li S, Chi H, Li YX, Chen HF et al (2012) Identification of cross-linked peptides from complex samples. Nat Methods 9:904-906

Yoshida H, Wada A (2014) The 100 S ribosome: ribosomal hibernation induced by stress. Wiley Interdiscip Rev RNA 5:723-732

Zhang X, Yan K, Zhang Y, Li N, Ma C, Li Z, Zhang Y, Feng B, Liu J, Sun $Y$ et al (2014a) Structural insights into the function of a unique tandem GTPase EngA in bacterial ribosome assembly. Nucl Acids Res 42:13430-13439

Zhang Y, Ma C, Yuan Y, Zhu J, Li N, Chen C, Wu S, Yu L, Lei J, Gao N (2014b) Structural basis for interaction of a cotranslational chaperone with the eukaryotic ribosome. Nat struct Mol Biol 21:1042-1046 